\title{
OPEN The potential ameliorative impacts of cerium oxide nanoparticles against fipronil-induced hepatic steatosis
}

\author{
Lamiaa Wasef ${ }^{1,12}$, Atef M. K. Nassar ${ }^{2}$, Yasser S. El-Sayed ${ }^{3}$, Dalia Samak ${ }^{3}$, Ahmed Noreldin ${ }^{4}$, \\ Norhan Elshony ${ }^{1}$, Hamida Saleh ${ }^{3}$, Yaser H. A. Elewa ${ }^{5,6,12}$, Shaimaa M. A. Hassan ${ }^{7,8}$, \\ Abdullah A. Saati ${ }^{9}$, Helal F. Hetta ${ }^{10 凶}$, Gaber El-Saber Batiha ${ }^{1 凶}$, Masakazu Umezawa ${ }^{11}$ \& \\ Hazem M. Shaheen ${ }^{1 \bowtie}$
}

Fipronil (FIP) is a phenylpyrazole insecticide that is commonly used in agricultural and veterinary fields for controlling a wide range of insects, but it is a strong environmentally toxic substance. Exposure to FIP has been reported to increase the hepatic fat accumulation through altered lipid metabolism, which ultimately can contribute to nonalcoholic fatty liver disease (NAFLD) development.

The present study aimed to examine the function of cerium oxide nanoparticles (CeNPs) in protecting against hepatotoxicity and lipogenesis induced by FIP. Twenty-eight male albino rats were classified into four groups: FIP ( $5 \mathrm{mg} / \mathrm{kg} / \mathrm{day}$ per os), CTR, CeNPs ( $35 \mathrm{mg} / \mathrm{kg} /$ day p.o.), and FIP + CeNPs (5 (FIP) +35 (CeNPs) $\mathrm{mg} / \mathrm{kg} /$ day p.o.) for 28 consecutive days. Serum lipid profiles, hepatic antioxidant parameters and pathology, and mRNA expression of adipocytokines were assessed. The results revealed that FIP increased cholesterol, height-density lipoprotein, triacylglyceride, low-density lipoprotein (LDL-c), and very-low-density lipoprotein (VLDL-c) concentrations. It also increased nitric oxide (NO) and malondialdehyde (MDA) hepatic levels and reduced glutathione peroxidase (GPX) and superoxide dismutase (SOD) enzyme activities. Additionally, FIP up-regulated the fatty acid-binding protein (FABP), acetyl Co-A carboxylase (ACC1), and peroxisome proliferator-activated receptor-alpha (PPAR- $\alpha$ ). Immunohistochemically, a strong proliferation of cell nuclear antigen (PCNA), ionized calcium-binding adapter molecule 1 (Iba-1), cyclooxygenase-2 (COX-2) reactions in the endothelial cells of the hepatic sinusoids, and increased expression of caspase 3 were observed following FIP intoxication. FIP also caused histological changes in hepatic tissue. The CeNPs counteracted the hepatotoxic effect of FIP exposure. So, this study recorded an ameliorative effect of CeNPs against FIP-induced hepatotoxicity.

\footnotetext{
${ }^{1}$ Department of Pharmacology and Therapeutics, Faculty of Veterinary Medicine, Damanhour University, Damanhour 22511, ElBeheira, Egypt. ${ }^{2}$ Pesticides Chemistry and Toxicology, Plant Protection Department, Faculty of Agriculture, Damanhour University, Damanhour, Egypt. ${ }^{3}$ Department of Veterinary Forensic Medicine and Toxicology, Faculty of Veterinary Medicine, Damanhour University, Damanhour, Egypt. ${ }^{2}$ Department of Histology and Cytology, Faculty of Veterinary Medicine, The Scientific Campus, Damanhour University, Damanhour, Egypt. ${ }^{5}$ Department of Histology and Cytology, Faculty of Veterinary Medicine, Zagazig University, Zagazig, Egypt. ' ${ }^{6}$ aboratory of Anatomy, Department of Biomedical Sciences, Graduate School of Veterinary Medicine, Hokkaido University, Sapporo, Hokkaido 060-0818, Japan. ${ }^{7}$ Histology and Cell Biology Department, Faculty of Medicine, Menoufia University, Shebeen El-Kom, Egypt. ${ }^{8}$ Department of Histology, College of Medicine, Batterjee Medical College, Aseer, Saudi Arabia. ${ }^{9}$ Department of Community Medicine \& Pilgrims Healthcare, Faculty of Medicine, Umm Al-Qura University, Mecca 24382, Saudi Arabia. ${ }^{10}$ Department of Medical Microbiology and Immunology, Faculty of Medicine, Assiut University, Assiut 71515, Egypt. ${ }^{11}$ Department of Materials Science and Technology, Faculty of Industrial Science and Technology Soga Laboratory, Tokyo University of Science, 9th Floor, Research Labs Building, 6-3-1 Niijuku, Katsushika, Tokyo 125-8585, Japan. ${ }^{12}$ These authors contributed equally: Lamiaa Wasef and Yaser H. A. Elewa. ${ }^{\boxplus}$ email: helal.hetta@uc.edu; gaberbatiha@gmail.com; dr_ hazemshaheen3010@yahoo.com
} 
Around the world, pesticides are widely used to control plant and animal pests but they have direct and/or indirect toxic effects on beneficial organisms ${ }^{1}$. Among pesticides, fipronil (FIP) [5-amino-3-cyano-1-(2,6-dichloro4-trifluoromethylphenyl) 4-fluoromethylsulfinyl pyrazole] is a second-generation phenylpyrazole insecticide ${ }^{2}$ extensively used in the veterinary clinical field against many pests, and ectoparasites ${ }^{3,4}$. It blocked the chloride channels regulated by GABA, resulting in an uncontrolled central nervous system (CNS) hyperexcitation and death $^{5}$. Fipronil toxic effect depends on the disturbance of the antioxidant and oxidant system balance through the over-accumulation of reactive oxygen species (ROS) in the cells ${ }^{6}$, especially of liver tissue, which is the main organ for insecticides-detoxification. This balance is a good indicator of exposure to toxic chemicals in hepatocytic mitochondria and endoplasmic reticulum ${ }^{8}$. Antioxidant/oxidant imbalance might lead to chemical changes in proteins and fat molecules structure resulting in the activation of lipid peroxidation (LPO) process ${ }^{9}$ and is often believed to enhance the hepatic cells oxidative injury ${ }^{10}$.

The accumulation of lipids in hepatic cells is more common in cases of exposure to toxic chemicals ${ }^{11}$ and leads to hepatitis and fibrosis ${ }^{11}$. Increased synthesis of triglycerides results in increased fatty acids (FA) accumulation in the liver. Consequently, mitochondrial oxidation of the free fatty acids (FFAs) damages the liver tissues, resulting in infiltration of neutrophil with subsequent ROS release and exacerbation of inflammatory reactions ${ }^{12,13}$. Alongside, cerium oxide nanoparticles (CeNPs) are among the most crucial metal-oxide nanoparticles, which play a technologically important role in synthesizing different industrial materials including polishing materials in the glass and optics industry, oxygen sensors, and ultraviolet filters ${ }^{14}$. CeNPs have gained much interest in biological applications due to their antioxidant properties. Based on the $\mathrm{Ce}^{3+} / \mathrm{Ce}^{4+}$ ratio in CeNPs surface, this antioxidant activity will be as follows: superoxide dismutase (SOD) mimetic activity ${ }^{15}$, catalase (CAT) mimetic activity, hydroxyl and nitric oxide (NO) scavenging property ${ }^{16}$. Therefore, CeNPs have been used in medicine ${ }^{15}$ and pharmacy ${ }^{17}$ due to their potent antioxidant activity in scavenging free radicals produced in the process of oxidative damage. Reducing ROS production could reduce inflammation and consequent tissue injury ${ }^{18}$. No earlier studies explained the correlation between CeNPs and FIP, thus the objective of the existing study was to examine the ameliorative impacts of CeNPs on hepatic tissue against sub-acute toxicity caused by FIP administration in male albino rats.

\section{Materials and methods}

Chemicals. Cerium oxide nanopowder $<25 \mathrm{~nm}$ particle size, (CAS Number: 1306-38-3) was purchased from Sigma-Aldrich Co., USA. The CeNPs were suspended in demineralized water at a $35 \mathrm{mg} / \mathrm{kg}$ bwt concentration. Fipronil solution ( $5 \mathrm{mg} / \mathrm{kg}$ bwt) was prepared by dissolving the commercial product FIPROGENT $80 \%$ (MAC-GmbH, Sigmarszell, Germany) in demineralized water.

Experimental animals. Twenty-eight healthy adult male albino rats (average weight $180 \pm 10 \mathrm{~g}$ ) were obtained from the Animal Breeding Unit, Faculty of Agriculture, Alexandria University. The animals were housed under a pathogen-free environment with controlled humidity, temperature $\left(22^{\circ} \mathrm{C}\right)$ and a $12 \mathrm{~h} \mathrm{light} /$ dark cycle. The animal experiments were performed according to the Laboratory Animals of the National Institutes of Health (NIH) Care and Use Guidelines, and the study protocol was approved by the local authorities of Damanhour University, Egypt (DMU-2019-0023). Two weeks before the experiment was conducted, the animals were allowed to acclimatize the testing facility condition. Afterward, the rats were caged equally into four experimental groups, each consisting of seven rats. Group 1-control group (CTR) rats were orally received saline. Group 2-animals have orally received FIP solution ( $5 \mathrm{mg} / \mathrm{kg}$ bwt, $1 / 20$ of the $\left.\mathrm{LD}_{50}\right)^{19,20}$. Group 3-the rats have orally received CeNPs solution ( $35 \mathrm{mg} / \mathrm{kg}$ body weight $)^{21}$. Group 4 -animals orally received FIP $(5 \mathrm{mg} / \mathrm{kg})$ and CeNPs $(35 \mathrm{mg} / \mathrm{kg}$ ) solutions using gastric tube daily. During the experimental period, rats were daily observed for any abnormal behavior and clinical signs.

Blood and tissue sampling. On the 28th day of the experiment, all rats were prohibited from feeding overnight, weighed individually, and euthanized using an anesthesia system containing xylazine and ketamine $\mathrm{HCl}$. Blood was gathered from the aortic vein, kept in anticoagulant-free test tubes, and the serum was isolated and kept at $-20^{\circ} \mathrm{C}$ until lipid profile determination. The liver was excised and rinsed using physiological saline $(\mathrm{NaCl} 0.9 \%)$, wiped using filter paper and split into two sections - the first section kept rapidly at $-80{ }^{\circ} \mathrm{C}$ for biochemical and gene expression levels and the second section was used for histopathological and immunohistochemical examination after fixing in four percent paraformaldehyde (PFA) diluted in phosphate buffer saline (PBS) solution.

Serum biochemical test. For examination of the serum lipid profile of the treated rats; triacylglycerol, cholesterol, HDL-c, LDL-c, and VLDL-c commercial kits were used, which were purchased from Bio-Diagnostics Co., Cairo, Egypt. The experiments were conducted following the manufacturer's instruction guidelines.

Oxidant/antioxidant parameters in liver tissue homogenates. Hepatic tissues were moistened using phosphate-buffered saline (PBS, $0.1 \mathrm{M}, \mathrm{pH}$ 7.4). Using a disposable homogenizer (Biomasher; Nippi, Inc., Tokyo, Japan), homogenates of ten percent from the hepatic tissues were then prepared in cold potassium phosphate buffer $(50 \mathrm{mM}, \mathrm{pH} 7.5)$. The resulted homogenates were centrifuged at $4{ }^{\circ} \mathrm{C}$ for $15 \mathrm{~min}$ at $10,000 \times g$. The supernatants were used for evaluating lipid peroxidation indicators: NO and malondialdehyde (MDA) ${ }^{22}$ and antioxidant biomarkers: glutathione peroxidase (GPx) and SOD activity ${ }^{23,24}$ following the manufacturers' guidelines (Bio-diagnostics CO., Cairo, Egypt). 


\begin{tabular}{|l|l|l|l|l|}
\hline Antibody & Source & Dilution & Antigen retrieval & Heating condition \\
\hline Rabbit polyclonal anti-Caspase3 & $\begin{array}{l}\text { (9662, Cell Signaling Technology, } \\
\text { Danvers, Ma, USA) }\end{array}$ & $1: 300$ & $10 \mathrm{mM}$ citrate buffer $(\mathrm{pH} 6.0)$ & $105^{\circ} \mathrm{C}, 20 \mathrm{~min}$ \\
\hline Rabbit polyclonal anti-Iba-1 & $(019-19741$, Wako Osaka, Japan) & $1: 1200$ & $10 \mathrm{mM}$ citrate buffer $(\mathrm{pH} 6.0)$ & $105^{\circ} \mathrm{C}, 20 \mathrm{~min}$ \\
\hline Goat polyclonal anti-PCNA & $\begin{array}{l}\text { (sc-9857, Santa Cruz Biotechnology, } \\
\text { CA, USA) }\end{array}$ & $1: 2000$ & Dako, $105^{\circ} \mathrm{C}, 20 \mathrm{~min}$ & $105^{\circ} \mathrm{C}, 20 \mathrm{~min}$ \\
\hline Rabbit polyclonal anti- Bax & (PU347-UP, San Ramon, Ca, USA) & $1: 30$ & None & None \\
\hline Rabbit monoclonal anti-Cox-2 & $\begin{array}{l}\text { (RM-9121-S0, Thermo Fisher } \\
\text { Scientific, Fremont, CA, USA) }\end{array}$ & $1: 100$ & $10 \mathrm{mM}$ citrate buffer (pH 6.0) & $105^{\circ} \mathrm{C}, 20 \mathrm{~min}$ \\
\hline
\end{tabular}

Table 1. List of antibodies, sources, working dilutions, and methods for antigen retrieval.

\begin{tabular}{|l|l|l|}
\hline Primer name & Accession number & Sequences \\
\hline Rattus norvegicus acetyl-CoA carboxylase alpha (Acaca), mRNA & NM_022193.1 & $\begin{array}{l}\text { F: GTTGGACAACGCCTTCACAC } \\
\text { R: GCGCATGGAATGGCAGTAAG }\end{array}$ \\
\hline Rattus norvegicus fatty acid binding protein 1 (Fabp1), Mrna & NM_012556.2 & $\begin{array}{l}\text { F: AGGACCTCATCCAGAAAGGGA } \\
\text { R: TGACCTTTTCCCCAGTCATGG }\end{array}$ \\
\hline $\begin{array}{l}\text { Rattus norvegicus peroxisome proliferator activated receptor alpha } \\
\text { (Ppara), mRNA }\end{array}$ & NM_013196.1 & $\begin{array}{l}\text { F: ACCTTGTGCATGGCTGAGAA } \\
\text { R: CCTTGGCAAATTCCGTGAGC }\end{array}$ \\
\hline Rattus norvegicus Caspase3 & NM_001284409.1 & $\begin{array}{l}\text { F: AGTTGGACCCACCTTGTGAG } \\
\text { R: AGTCTGCAGCTCCTCCACAT }\end{array}$ \\
\hline Rattus norvegicus Bcl-2 like protein 4 & NM_007527.3 & $\begin{array}{l}\text { F: CACCAGCTCTGAACAGATCATGA } \\
\text { R: TCAGCCCATCTTCTTCCAGATGGT }\end{array}$ \\
\hline
\end{tabular}

Table 2. Primer sequences and accession number used for RT-qPCR.

Hepato-histological examination. The fixed samples were treated using the traditional paraffin embedding method, including drying in ascending grades of ethanol, disinfected in three changes of xylene and melted paraffin finished by inserting it at $65^{\circ} \mathrm{C}$ in paraffin wax. Hematoxylin and eosin (H\&E) were used to stain four $\mu \mathrm{m}$ thick sections as previously detected by Bancroft and Layton ${ }^{25}$ and Periodic acid Schiff (PAS) based on Layton and Bancroft ${ }^{26}$. Semi-quantitative scoring of cardiac lesions was calculated based on Gibson-Corley, et al. ${ }^{27}$. Briefly, the lesions in 10 fields were collected and summed randomly from each slide for each rat. The lesions were blindly recorded (Score scale: $0=$ normal; $1 \leq 25 \% ; 2=26-50 \% ; 3=51-75 \% ; 4=76-100 \%$ ).

Immunohistochemical examination. Working dilutions, sources, methods, and antibodies for antigen recovery were listed in Table 1 . The immunohistochemical technique in liver sections was investigated based on the method identified by Noreldin, et al. ${ }^{28}$ and Noreldin, et al. ${ }^{29}$. Briefly, the paraffin sections were prepared with a thickness of $4 \mu \mathrm{m}$, deparaffinized by xylene and re-moistened in graded alcohol and washed with distilled water. Afterward, endogenous peroxidase was deactivated by $3 \% \mathrm{H}_{2} \mathrm{O}_{2}$ in absolute methanol for 30 min at $4{ }^{\circ} \mathrm{C}$ and washed again using PBS, blocking the nonspecific reaction at room temperature with $10 \%$ normal blocking serum for $60 \mathrm{~min}$. Then, the sections were incubated overnight at $4{ }^{\circ} \mathrm{C}$ with the primary antibodies, washed with PBS, incubated for 60 min with biotin-conjugated goat anti-rabbit IgG antiserum or rabbit anti-goat IgG antiserum (Histofine kit, Nichirei Corporation) according to the species' primary antibody hosted. Then the sections were incubated for $30 \mathrm{~min}$ with streptavidin-peroxidase conjugate (Histofine kit, Nichirei Corporation) after washing with PBS. The streptavidin-biotin complex was further incubated for 3 min with a solution of 3,3'-diaminobenzidine tetrahydrochloride (DAB) $-\mathrm{H}_{2} \mathrm{O}_{2}, \mathrm{pH}$ 7.0. Finally, the sections were rinsed with distilled water and used Mayer's hematoxylin counterstain. A digital camera (Leica EC3, Leica, Germany) connected to a microscope (Leica DM500, Leica, Germany) was used to capture micrographs of the prepared sections. ImageJ software (National Institutes of Health, Bethesda, MD, USA) was used for immunostaining intensities' quantification $^{30}$. The mean of the inverse density of 10 randomly selected fields from different parts of 8 rats in each group was calculated byVis et al. ${ }^{31}$.

Quantitative reverse transcription-polymerase chain reaction (RT-qPCR). RNA-Spin ${ }^{\text {tm }}$ total $^{\text {t }^{2}}$ RNA extraction kits (Cat. \#17211) (INTRON biotechnology Inc. was used to extract total RNA from the liver tissues. Total RNA ( $1 \mathrm{mg}$ ) was used as a template for the first strand of complementary DNA (cDNA) using Maxima First Strand cDNA synthesis Kits from iNtRON Biotechnology Inc (Cat. \#EZ00SS). Quantitative RTPCR was conducted using Thermo Scientific Maxima SYBR Green/ROX qPCR PreMix kits from iNtRON Biotechnology Inc (Cat. \#RT500S). The primers were acetyl-CoA carboxylase alpha Rattus norvegicus, peroxisome proliferator-activated receptor alpha (PPAR- $\alpha$ ), Fabp1, Rattus norvegicus caspase3, and Rattus norvegicus Bcl-2 like protein (Table 2). The values of target genes have been standardized to household expression level, GAPDH.

Statistical analysis. Data were described as mean \pm SEM. Results were analyzed statistically by one-way (ANOVA) test using the Statistical Analysis System (SAS) software version 13.2 (SAS, 2016). Considerable 


\begin{tabular}{|l|l|l|l|l|l|}
\hline Group & TAG $(\mathbf{m g} / \mathbf{d L})$ & VLDLc $(\mathbf{m g} / \mathbf{d L})$ & LDLc $(\mathbf{m g} / \mathbf{d L})$ & Cholesterol $(\mathbf{m g} / \mathbf{d L})$ & HDLc $(\mathbf{m g} / \mathbf{d L})$ \\
\hline CRT & $70.4125 \pm 0.38534^{\mathrm{b}}$ & $14.1825 \pm 0.78979^{\mathrm{a}}$ & $39.9725 \pm 2.64559^{\mathrm{b}}$ & $115.0000 \pm 0.40825^{\mathrm{b}}$ & $45.3500 \pm 1.28225^{\mathrm{b}}$ \\
\hline FIP & $88.2000 \pm 1.37174^{\mathrm{a}}$ & $15.9900 \pm 1.01985^{\mathrm{a}}$ & $66.0900 \pm 2.70945^{\mathrm{a}}$ & $137.1250 \pm 1.63777^{\mathrm{a}}$ & $66.8750 \pm 1.73656^{\mathrm{a}}$ \\
\hline CeNPs & $66.0250 \pm 0.83902^{\mathrm{b}}$ & $13.2175 \pm 0.16815^{\mathrm{a}}$ & $31.3875 \pm 2.64483^{\mathrm{b}}$ & $105.2125 \pm 0.79441^{\mathrm{c}}$ & $41.7750 \pm 1.18348^{\mathrm{b}}$ \\
\hline FIP +CeNPs & $65.8125 \pm 1.31694^{\mathrm{b}}$ & $14.4725 \pm 1.06092^{\mathrm{a}}$ & $34.3950 \pm 2.84348^{\mathrm{b}}$ & $104.3425 \pm 1.55696^{\mathrm{c}}$ & $46.8500 \pm 1.73133^{\mathrm{b}}$ \\
\hline
\end{tabular}

Table 3. Effects of Fipronil and CeNPs intake on Serum lipid profile indices in rats. The effect of cerium oxide nanoparticles (CeNPs) on serum lipid profile concentrations in FIP intoxicated rats. All values are expressed as the mean $\pm S E, n=7$. Means with different superscript letters $(\mathrm{a}, \mathrm{b}, \mathrm{c})$ are statistically significant at $(\mathrm{p} \leq 0.05)$. FIP Fipronil, CeNPs cerium oxide nanoparticles, TAG triacylglycerides, VLDLc very-low density lipoproteins, $L D L c$ low density lipoproteins, $H D L c$ high density lipoproteins. Values with different superscript letters within the same column are significantly different $(P \leq 0.05$, One-way ANOVA with Tukey's HSD post hoc test).

\begin{tabular}{|l|l|l|l|l|}
\hline Group & MDA $(\mathbf{n m o l} / \mathbf{m g})$ & NO $(\mu \mathbf{m o l} / \mathbf{m g})$ & GPx $(\mathbf{U} / \mathbf{m g})$ & SOD $(\mathbf{U} / \mathbf{m g})$ \\
\hline CRT & $0.3825 \pm 0.00479^{\mathrm{b}}$ & $56.5825 \pm 1.14776^{\mathrm{bc}}$ & $42.4325 \pm 2.19678^{\mathrm{a}}$ & $7.7000 \pm 0.48642^{\mathrm{a}}$ \\
\hline FIP & $0.6475 \pm 0.02016^{\mathrm{a}}$ & $86.5925 \pm 0.50688^{\mathrm{ab}}$ & $25.6025 \pm 1.30649^{\mathrm{b}}$ & $4.1650 \pm 0.26247^{\mathrm{b}}$ \\
\hline CeNPs & $0.2375 \pm 0.00750^{\mathrm{c}}$ & $49.8525 \pm 1.33769^{\mathrm{c}}$ & $45.9525 \pm 1.16427^{\mathrm{a}}$ & $9.1800 \pm 0.47450^{\mathrm{a}}$ \\
\hline FIP CeNPs & $0.4250 \pm 0.01708^{\mathrm{b}}$ & $53.8875 \pm 1.99681^{\mathrm{bc}}$ & $41.9800 \pm 1.12886^{\mathrm{a}}$ & $8.1450 \pm 0.27834^{\mathrm{a}}$ \\
\hline
\end{tabular}

Table 4. Effects of Fipronil and CONPs intake on hepatic oxidative/antioxidative indices in rats. The effect of cerium oxide nanoparticles (CeNPs) on liver tissue lipid peroxidation and activities of antioxidant enzymes in FIP intoxicated rats All values are expressed as the mean $\pm S E, n=7$. Means with different superscript letters $(\mathrm{a}, \mathrm{b}, \mathrm{c})$ were significantly different at $(\mathrm{P} \leq 0.05)$. FIP Fipronil, CeNPs cerium oxide nanoparticles, MDA Malondialdehyde, SOD Superoxide dismutase, GPx Glutathione peroxidase, NO Nitrogen oxide. Values with different superscript letters within the same row are significantly different $(P \leq 0.05$, One-way ANOVA with Tukey's HSD post hoc test).

means have been compared with multiple reference checks of Tukey's post-hoc. Results at $P<0.05$ were considered statistically significant.

\section{Results}

Signs of toxicity. No obvious clinical signs or symptoms noticed all over the experimental period on rats that were exposed to FIP or/and CeNPs.

Serum biochemical findings. The FPN-intoxicated group showed significant elevation $(P<0.05)$ in the serum levels of cholesterol (19.0\%), TAG (25.2\%), LDL-c (66.0\%) and HDL-c (47.6\%) when compared with the CTR one (Table 3). Meanwhile, rats treated with CeNPs and FIP + CeNPs exhibited remarkable reductions $(P \leq 0.05)$ in serum cholesterol levels by 8.5 and $9.3 \%$, respectively. Rats treated with CeNPs and FIP + CeNPs had similar content of TAG, VLDL-c, LDL-c, and HDL-c to that of the CTR group. The VLDL-c levels were not different in the serum of all treated groups (Table 3 ).

Liver lipid peroxidation and antioxidative indices. The results presented in Table 4 revealed that the FIP-treated group showed substantial increase $(P \leq 0.05)$ in MDA $(68 \%)$ concentrations and decrease in GPx (39\%) and SOD (46\%) enzymes activities in the liver tissue in relative to the CTR one. The concentrations of MDA in liver tissue (37\%) in CeNPs-treated rats was reduced significantly $(P \leq 0.05)$, while GPx and SOD enzyme activities were similar to normal CTR values (Fig. 2). Concentrations of serum NO were nearly comparable in CTR, CeNPs, and FIP + CeNPs groups. The FIP toxic effects on hepatic GPx, MDA, SOD, and NO were substantially reduced $(P \leq 0.05)$ by CeNPs administration indicating the effect of CeNPs in alleviating oxidative damage caused by FIP.

Histopathological investigation of hepatic tissue. The histological findings revealed a polygonal hepatocyte producing substantial anastomosis plaques in the liver tissue in the CTR animals with acidophilic cytoplasm (Fig. 1A). Hepatic cells exhibited one or two large central round heavy hematoxylin-stained nuclei. Moreover, one or more nucleoli were detected in some hepatic cells (Fig. 1A). Hepatocyte plates and the hepatic capillaries barriers (sinusoids) laminated the Disse's space, while hepatic capillary walls were bordered by Kupffer cells (Fig. 1A) and distinguished primarily by elongated and heavily stained nuclei. The tissues of the CeNPs group didn't show any histopathological effects (Fig. 1B). In contrast, the FIP group revealed portal vein congestion surrounded with lymphocytic infiltration, lymphocytic aggregation in between massive fatty degeneration, congested central vein, necrotic foci, and nuclear condensation (Fig. 1C-E). It was noticed that CeNPs protected hepatic cells against FIP adverse effects, where it restored the normal architecture of liver tissues (Fig. 1F). The 

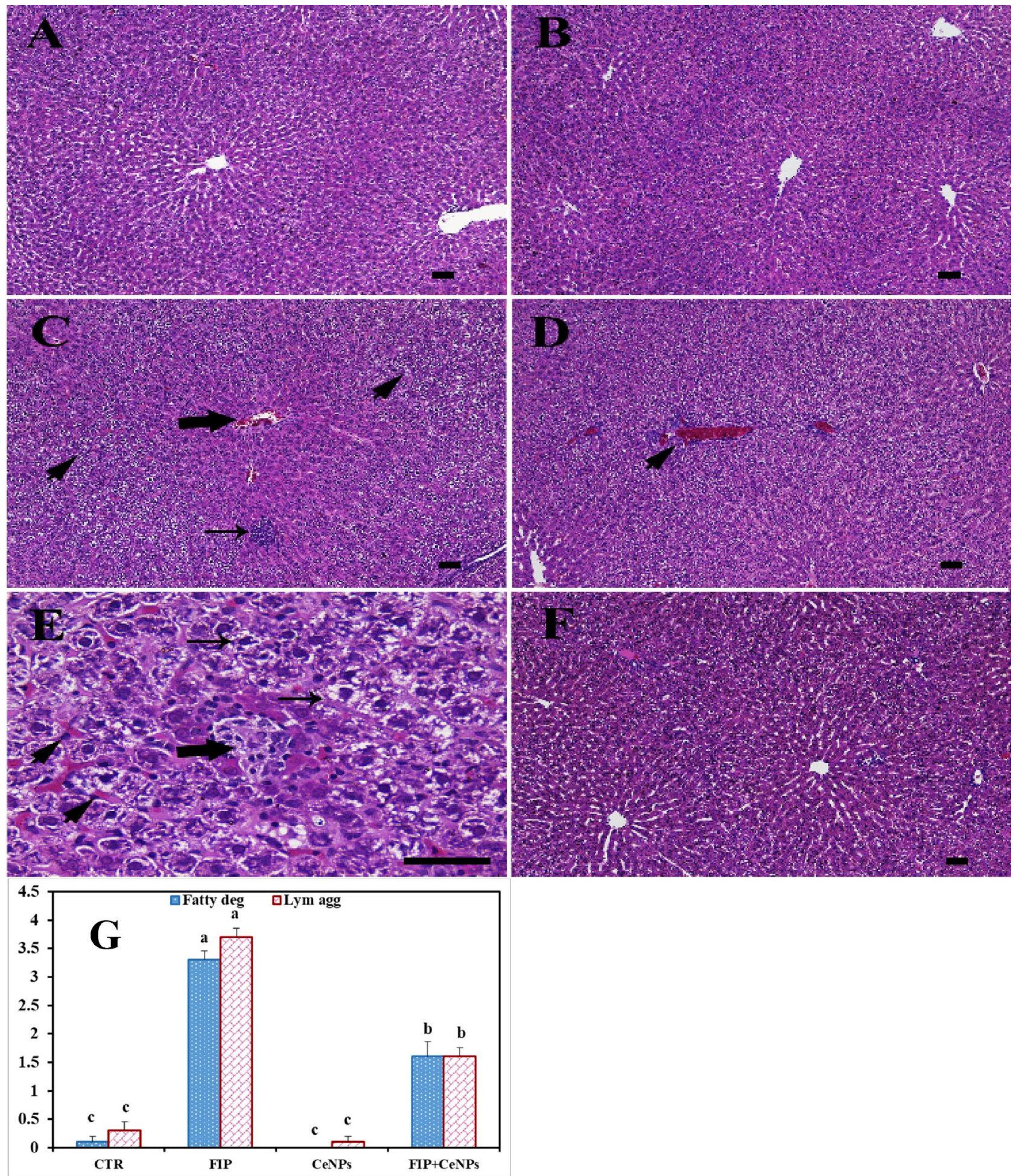

Figure 1. Histopathological examination of rat liver. (A) Negative control group. (B) CeNPs group. (C-E) FIP group showing in (C) congested central vein (arrow), massive fatty degeneration in the periportal areas (arrowheads) and lymphocytic aggregation (arrow) in between massive fatty degeneration (arrowheads). (D) Highly congested portal vein surrounded with lymphocytic infiltration (arrowhead). (E) Necrotic foci (thick arrow), congested liver sinusoids (arrowheads) and fatty degeneration (thin arrows). (F) FIP group that treated with CeNPs. Scale bar $=50 \mu \mathrm{m}$. (G) H\&E semi quantitative scoring of hepatic fatty degeneration and lymphocytic aggregations. Data expressed as Mean \pm SE, analyzed using one-way ANOVA at $P \leq 0.05$, column with different letters $(\mathrm{a}, \mathrm{b} \& \mathrm{c})$ indicate significant difference among the values of different groups. 

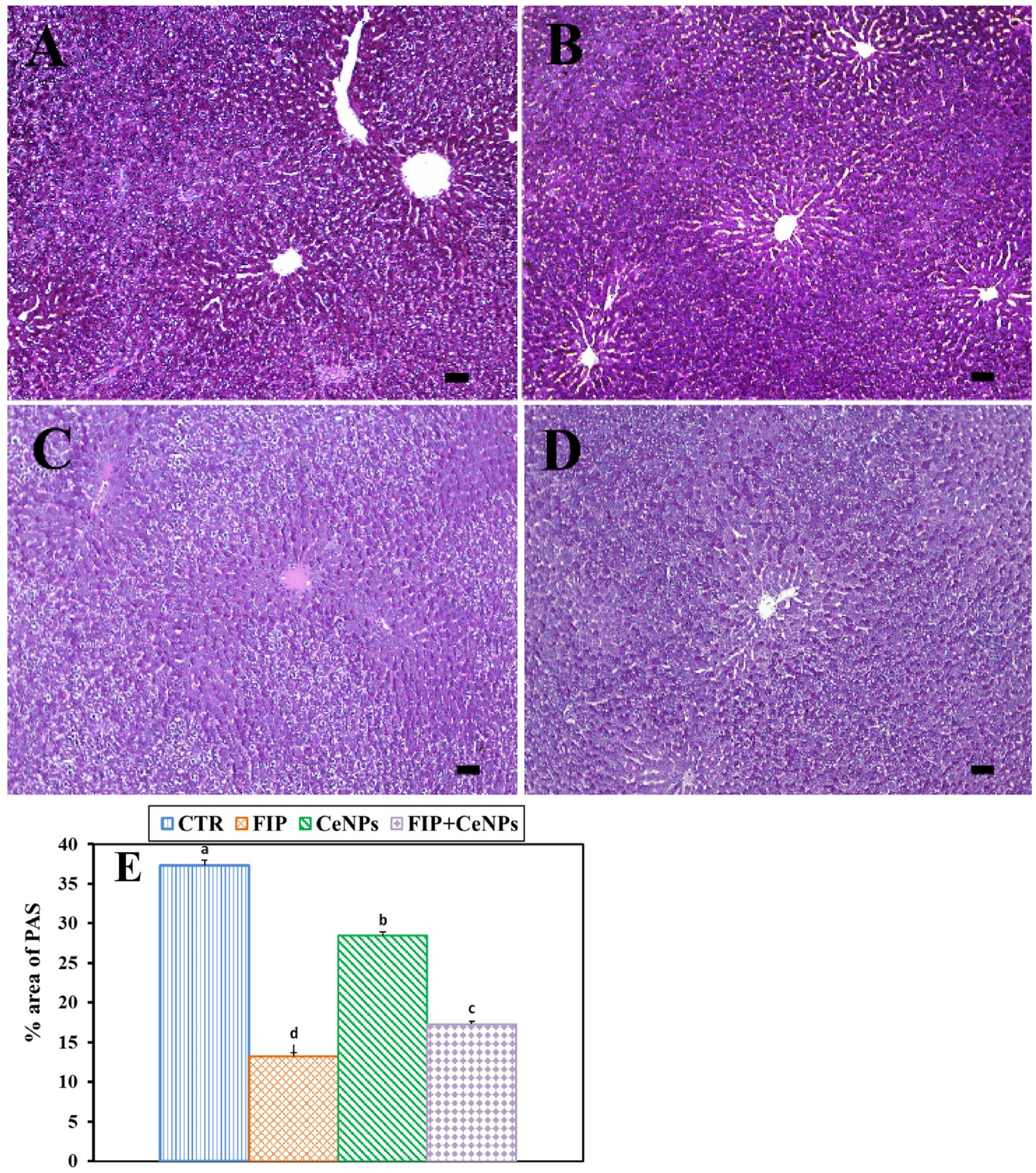

Figure 2. Histochemical staining of rat liver by periodic acid Schiff (PAS). (A) Negative control group. (B) CeNPs group. (C) FIP group. (D) FIP group that treated with the CeNPs group. Scale bar $=50 \mu \mathrm{m}$. (E) Quantification of PAS in the hepatic tissues in different groups Data expressed as Mean \pm SE, analyzed using one-way ANOVA at $P \leq 0.05$, column with different letters (a, b, c, \& d) indicate significant difference among the values of different groups.

FIP treatment significantly increased the fatty bodies' degeneration and lymph aggregation compared to CeNPs and the CTR group, while CeNPs significantly countered these effects (Fig. 1G).

CeNPs groups had the greatest PAS distribution in all hepatocytes (Fig. 2A,B). Also, FIP caused a weak and uneven distribution of PAS and decreased glycogen content (Fig. 2C) in relation to the CTR one. Additionally, the FIP group that was treated with CeNPs had a moderate PAS reaction (Fig. 2D). FIP showed a significant decrease 

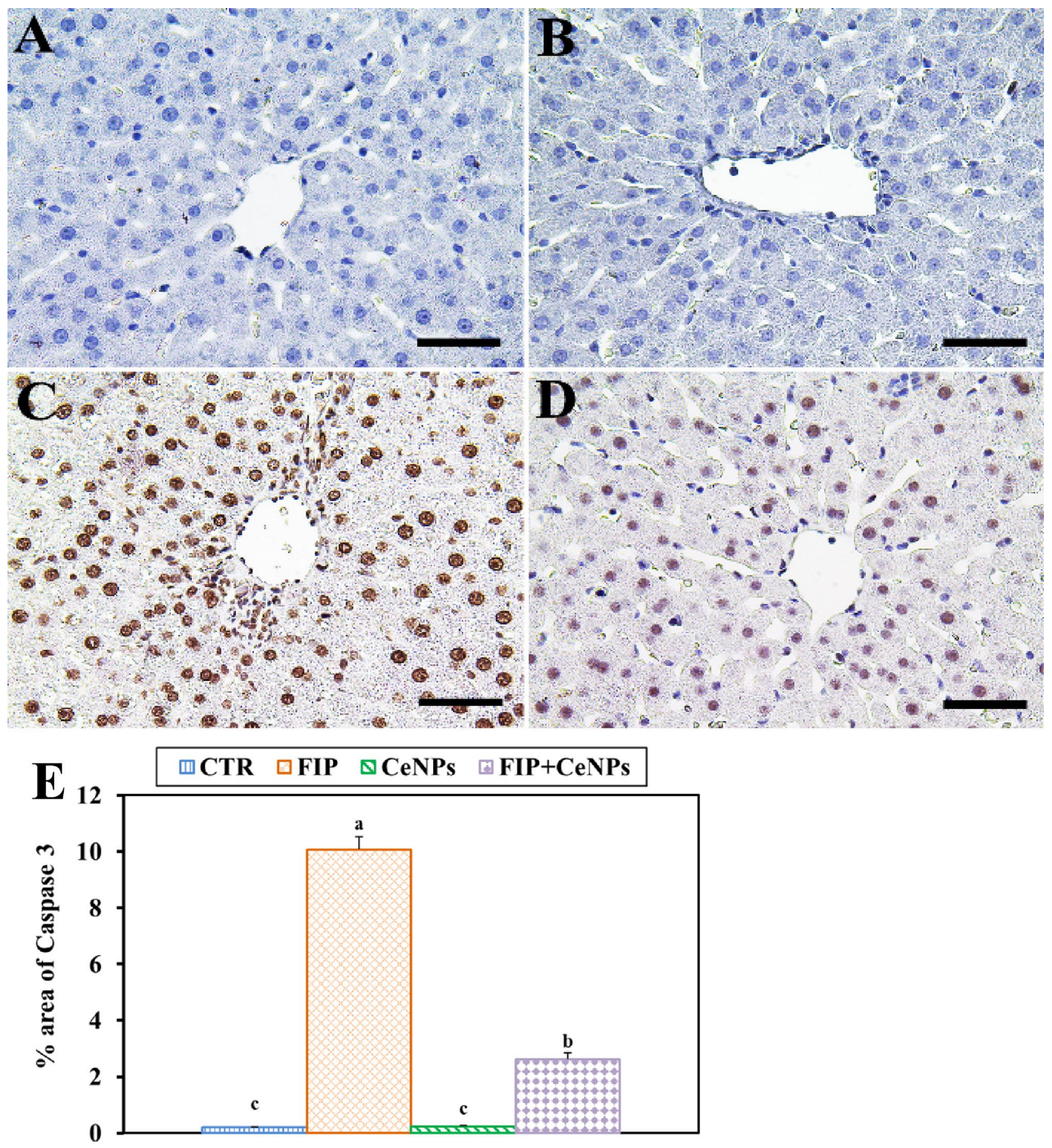

Figure 3. Immunohistochemical staining of rat liver by Caspase3. (A) Negative control group. (B) CeNPs group. (C) FIP group. (D) FIP group that treated with CeNPs. Scale bar $=50 \mu \mathrm{m}$. (E) Quantification of Caspase 3 in the hepatic tissues in different groups. Data expressed as Mean \pm SE, analyzed using one-way ANOVA at $P \leq 0.05$, column with different letters ( $\mathrm{a}, \mathrm{b} \& \mathrm{c}$ ) indicate significant difference among the values of different groups.

in PAS distribution concerning CTR and the CeNPs-treated group. CeNPs showed a high even distribution of PAS reaction in all hepatic lobules when combined with the FIP (Fig. 2E).

Immunohistochemistry. The FIP treatment showed a significant increase in caspase 3 reaction concerning CTR- and CeNPs-treated groups. On the other hand, the FIP-treated group was protected with cerium as shown by a very weak caspase 3 reaction (Fig. 3 ). 

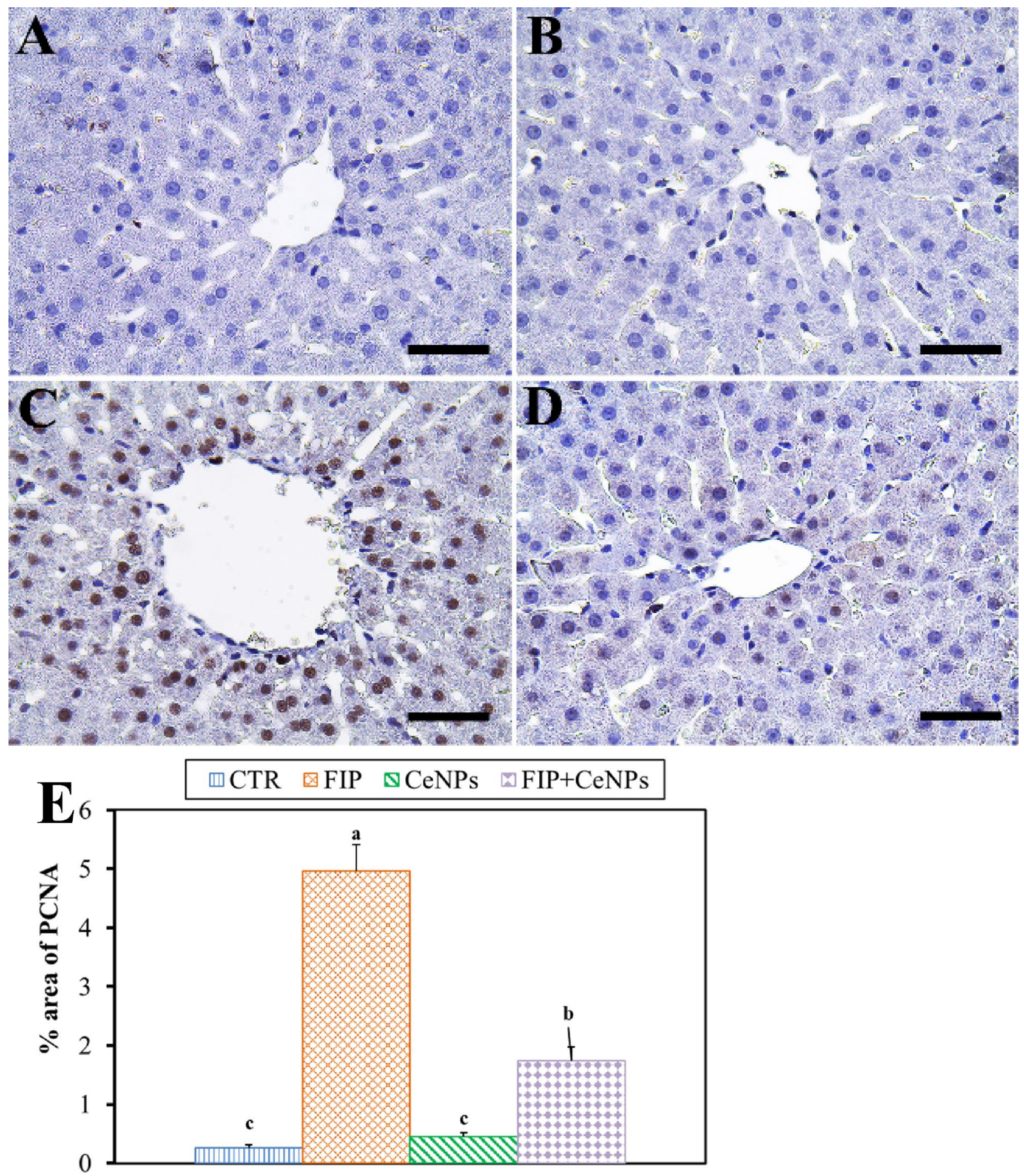

Figure 4. Immunohistochemical staining of rat liver by proliferating cell nuclear antigen (PCNA). (A) Negative control group. (B) CeNPs group. (C) FIP group. (D) FIP group that treated with CeNPs. Scale bar $=50 \mu \mathrm{m}$. (E) Quantification of PCNA in the hepatic tissues in different groups. Data expressed as Mean \pm SE, analyzed using one-way ANOVA at $P \leq 0.05$, column with different letters ( $\mathrm{a}, \mathrm{b} \& \mathrm{c}$ ) indicate significant difference among the values of different groups.

Also, FIP-treated group showed strong PCNA reaction in the nuclei of most hepatocytes compared to CTR and CeNPs groups that showed negative PCNA reaction in the nuclei of hepatocytes, while FIP + CeNPs-treated group showed nearly negative PCNA reaction in nuclei of the hepatocytes (Fig. 4). 
Immunostaining of rat liver tissues by massive ionized calcium-binding adapter molecule1 (Iba-1) in the case of the FIP-intoxicated group showed a strong inflammatory process via strong cyclooxygenase (COX-2) reaction and Iba-1 positive hepatic macrophage in the hepatic sinusoids in comparison to fipronil group that treated with cerium nanoparticles. The latter group showed low IBA1 positive hepatic macrophage in the hepatic sinusoids. CTR and CeNPs groups showed normal distribution of the Iba-1positive hepatic macrophage in the hepatic sinusoids (Fig. 5) with a negative COX-2 reaction (Fig. 6). CeNPs attenuated FIP impacts on the endothelial cells of the hepatic sinusoids and showed a moderate reaction (Fig. 6).

mRNA expression of FABP, ACC, PPAR- $\alpha$, Caspase3, and Bcl-2. The results of mRNA expressions of FABP, ACC, PPAR- $\alpha$, caspase 3 and Bcl-2 genes in liver tissues were presented in Table 5 . The results revealed up-regulation $(P \leq 0.05)$ in the comparative mRNA expressions of FABP, ACC, PPAR- $\alpha$, and caspase 3 , while exhibited down-regulation in the Bcl-2 gene in the liver tissue of rats that received FIP when compared with the CTR animals. Meanwhile, CeNPs treatment down-regulated the mRNA expression of ACC and caspase 3 and up-regulated the FABP, PPAR- $\alpha$, and Bcl-2 compared to CTR. In the case of the FIP group that was treated with CeNPs, significant up-regulation in FABP, PPAR- $\alpha$ and Bcl-2 were observed. On the other hand, ACC and caspase 3 mRNA expression were significantly down-regulated (Table 5).

\section{Discussion}

Hepatoxicity changes induced by FIP might be due to the imbalance of the antioxidant system, which might lead to the formation of ROS that activates the apoptotic process and disturbances in the lipid profile of rats ${ }^{32,33}$. Current results showed that CeNPs was a chemoprotective agent against FIP-induced hepatotoxicity. The hepatic cells were documented to have a significant and critical function in lipogeneses and glucose metabolism processes ${ }^{34}$. The disturbance of lipid and glucose metabolism might be observed by the excess accumulation of FA in the hepatic cells ${ }^{35}$. Consequently, increasing hepatic FA uptake ${ }^{36}$ leads to an increase in the hepatic triglyceride (TG) levels, which induces NAFLD development ${ }^{37}$. The changes in lipid profile might be caused by the accumulation of a high level of FA in circulation and hepatic lipogenesis, resulting in TG accumulation in the liver while dietary lipids represent a large percentage of intrahepatic lipids ${ }^{38,39}$.

The current study explained a decreased weight gain in CeNPs-treated rats relative to CTR ones. Also, the animals treated with FIP showed a remarkable elevation in serum lipid profile (TAG, HDL-c, LDL-c, and cholesterol) compared to CTR, CeNPs, and FIP + CeNPs groups. The significant modification in lipids might be due to the oxidative stress produced by FIP, which ultimately leads to liver inflammation and injury. These results indicated that FIP induced lipogenesis and lipid accumulation via increased expression of FABP and ACC1 in comparison to the CeNPs-treated group, which showed downregulation of ACC1 along with the up-regulation of FABP like the CTR groups. Activated AMPK (adenosine monophosphate-activated protein kinase) that phosphorylates the main proteins associated with controlling lipid and carbohydrate metabolism, followed by ATP inhibition that consumes anabolic pathways, such as cholesterol, isoprenoid, and FA synthesis, hepatic gluconeogenesis ${ }^{40}$ and induces lipolysis ${ }^{41,42}$. Some studies revealed that FIP increases adipogenesis by downregulating AMPKa, which disrupts lipid metabolism, which may demonstrate the high serum cholesterol level ${ }^{20,33}$. Fipronil insecticide has been reported to raise the levels of intracellular $\mathrm{Ca}^{+2}$ by altering the plasma membrane permeabilization ${ }^{43}$, leading to a disruption of adipogenesis and lipid metabolism process by the pathway mediated by Ca MKK $\beta$ and AMPK ${ }^{44}$.

FIP substantially elevated fatty acid synthase (FAS) and acetyl Co-A carboxylase (ACC) expression (the two rate-limiting enzymes for lipogenesis) ${ }^{45}$ when compared with CTR group. Likewise, FABP (a protein that transports FA in the cytoplasm for metabolic process or storage) expression ${ }^{46}$, was significantly enhanced by FIP therapy relative to $\mathrm{CTR}^{45}$. Regarding CeNPs, interestingly, Rocca et al. ${ }^{47}$ identified CeNPs as a new anti-obesity pharmaceutical formula after being tested in vitro and in vivo. They stated that CeNPs interfere with the adipogenic mechanism by decreasing the mRNA transcription of genes included in adipogenesis through inhibiting the accumulation of triglycerides found in 3T3-L1 pre-adipocytes. Intraperitoneal injection of CeNPs at a dose of $0.5 \mathrm{mg} / \mathrm{kg}$ did not show toxic symptoms in rats, however, a significant decrease in body weight and insulin, leptin, glucose, and TG plasma levels are observed in comparison to CTR group ${ }^{47}$. Our results are consistent with other studies that demonstrate the ability of CeNPs to activate AMPK which indicates inhibition of adipogenesis with decreased PPARaC/EBPa expression as well as adipogenic markers including ACC and FAS ${ }^{48,49}$.

Lipogenesis inhibition due to ACC phosphorylation may be the major regulatory step in FA synthesis and oxidation $^{50}$. ACC stimulates the malonyl-CoA synthesis, which is a FA synthesis substrate and is inhibited by AMPK-mediated ACC phosphorylation ${ }^{51}$. Metabolism enhancement is considered as one of the anti-inflammatory actions of CeNPs mechanisms since that results reported herein have demonstrated that CeNPs substantially decreased the weight gain of rats, which might reduce the visceral obesity of rats (A. Rocca, S. Moscato, F. Ronca, S. Nitti, V. Mattoli, M. Giorgi, G. Ciofani, Pilot in vivo investigation of cerium dioxide nanoparticles as a novel anti-obesity pharmaceutical formulation, Nanomed. Nanotechnol., Biol. Med. 11 (7) (2015) 1725-1734). The mass of visceral adipose tissue in CeNPs-treated rats was approximately twice less than CTR ${ }^{52}$. PPARa is the most prevalent isotype in hepatic cells and participates in several lipid metabolism aspects ${ }^{53}$, such as FA synthesis, degradation, storage, transport, lipoprotein metabolism and ketogenesis throughout fasting. PPAR $\alpha$ coordinates various de novo lipid synthesis pathways in the fed state to provide FA for hepatic TG storage during starvation times ${ }^{54}$. PPARa's mRNA expression in rats was the highest in tissues with high FA oxidation levels, such as kidney, heart, liver, and brown adipose tissue ${ }^{55,56}$. High-fat diet administration is often related to PPARa target genes hepatic expression participates in FA oxidation in wild-type mice, and it has been proposed the adaptive or protective effect of PPAR ${ }^{57,58}$. Few reports have investigated the outcomes of PPARa for treatments for NAFLD ${ }^{59}$. The improvement of $\beta$-FAO by PPAR $\alpha$ agonist ${ }^{60}$ might protect the mice from induced liver injury ${ }^{61}$. Also, the recent study explained the high PPAR $\alpha$ expression in FIP-treated rats that might be 

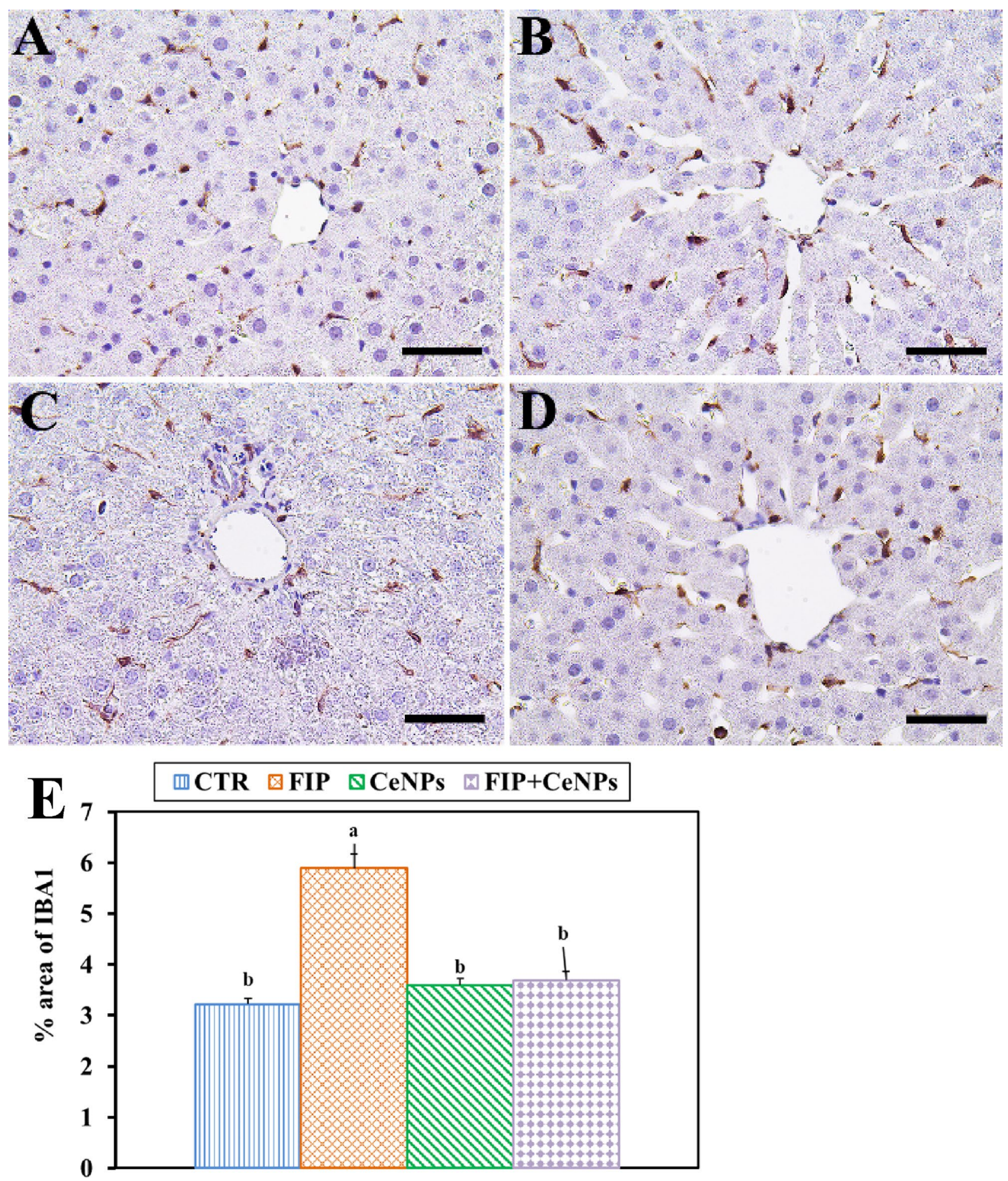

Figure 5. Immunohistochemical staining of rat liver by ionized calcium-binding adapter molecule 1 (Iba-1). (A) Negative control group. (B) CeNPs group. (C) FIP group. (D) FIP group that treated with CeNPs. Scale $\mathrm{bar}=50 \mu \mathrm{m}$. (E) Quantification of I Iba-1 in the hepatic tissues in different groups. Data expressed as Mean $\pm \mathrm{SE}$, analyzed using one-way ANOVA at $\mathrm{P} \leq 0.05$, column with different letters ( $\mathrm{a} \& \mathrm{~b}$ ) indicate significant difference among the values of different groups.

due to the increased level of FFAs and b-oxidation that usually caused by FFAs load in the mitochondria. This increases the load on the endoplasmic reticulum, which leads to ROS production causing oxidative stress and 

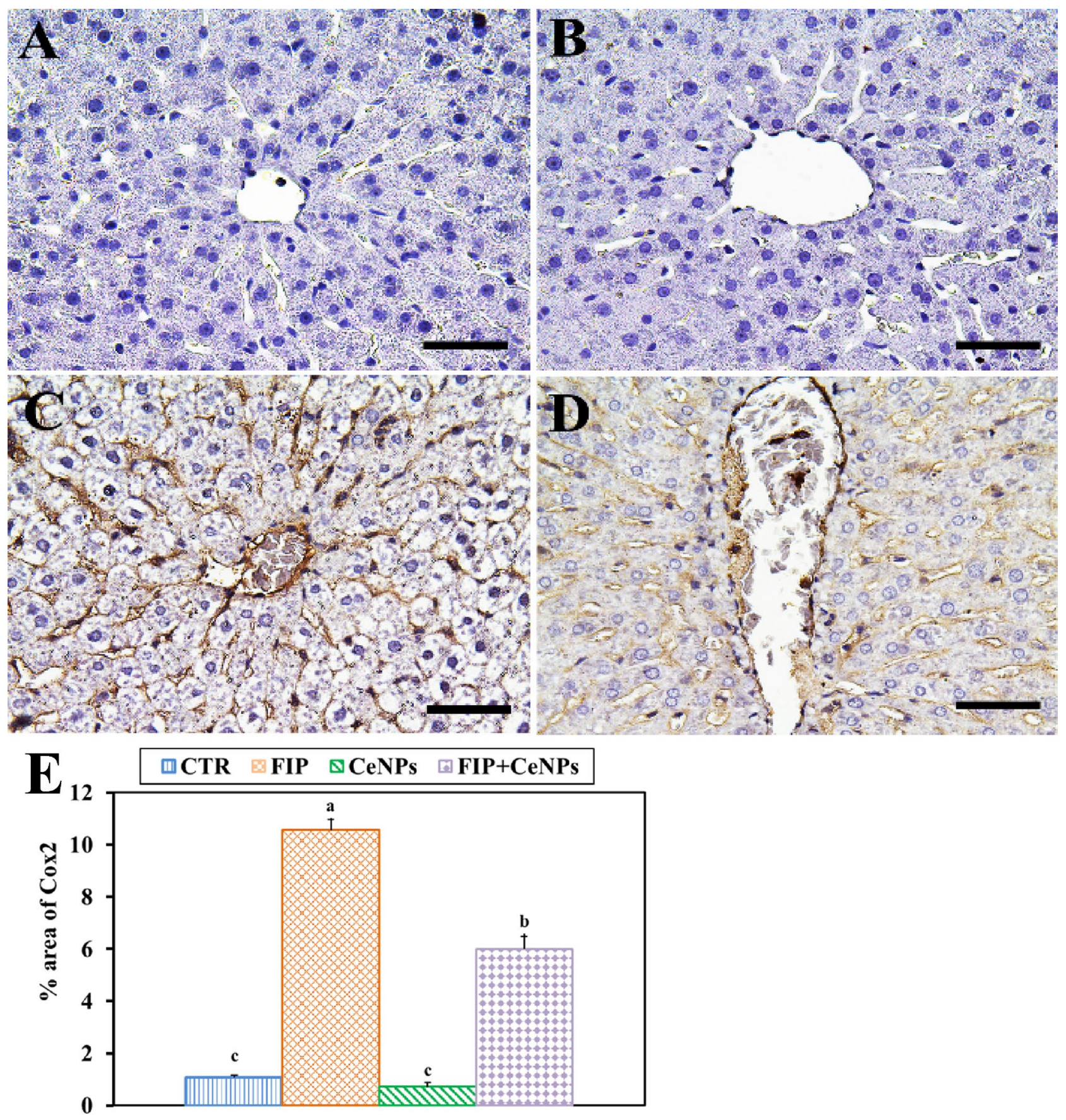

Figure 6. Immunohistochemical staining of rat liver by COX-2. (A) negative control group. (B) CeNPs group. (C) FIP group. (D) FIP group that treated with CeNPs. Scale bar $=50 \mu \mathrm{m}$. (E) Quantification of COX-2 in the hepatic tissues in different groups. Data expressed as Mean $\pm \mathrm{SE}$, analyzed using one-way ANOVA at $P \leq 0.05$, column with different letters $(a, b$ \& $c)$ indicate significant difference among the values of different groups.

\begin{tabular}{|l|l|l|l|l|l|}
\hline Gene group & FABP & PPAR $\boldsymbol{\alpha}$ & ACC & Bcl2 like protein 4 & Caspase3 \\
\hline FIP & $2.230447721 \pm 0.423$ & $4.363039 \pm 0.953$ & $2.17347 \pm 0.65$ & $0.736624 \pm 0.125$ & $1.596966 \pm 0.313$ \\
\hline CeNPs & $1.28877463 \pm 0.329$ & $1.395388 \pm 0.351$ & $0.076875 \pm 0.021$ & $1.670562 \pm 0.346$ & $0.240149 \pm 0.051$ \\
\hline FIP +CeNPs & $1.428333957 \pm 0.376$ & $1.813781 \pm 0.40459$ & $0.846941 \pm 0.203$ & $1.081225 \pm 0.165$ & $0.82302 \pm 0.143$ \\
\hline
\end{tabular}

Table 5. mRNA expression of fatty acid-binding protein. The effect of cerium oxide nanoparticles (CeNPs) on liver mRNA expressions of FABP (fatty acid-binding protein), PPAR $\alpha$ (peroxisome proliferator activated receptor- alpha), ACC (Acetyl COA Carboxylase), Bcl2 Like protein 4 and Caspase 3 in FIP intoxicated rats. Data are expressed as Mean \pm SE $(\mathrm{n}=7)$. FIP Fipronil, CeNPs cerium oxide nanoparticles. 
inflammatory pathway activation ${ }^{62}$. Besides its role in metabolism regulation, PPAR $\alpha$ is also believed to have anti-inflammatory activity ${ }^{63}$.

There has been cumulative evidence that pesticide toxicity inhibits redox homeostasis as well as oxidative damage induction. Several studies suggested that redox homeostasis disturbance was triggered during FIP toxicity was because of high ROS production ${ }^{33,64,65}$. Hepatotoxicity induced by FIP in this study might be due to increased levels of MDA and NO (the indicator of LPO) because of the high reactive oxygen metabolites production especially the hydroxyl radicals ${ }^{33,66}$, LPO play role in the disruption of the integrity of cellular membranes and implicated in liver injuries ${ }^{67}$. ROS can target cell membranes and other cellular molecules, resulting in protein oxidation, lipid peroxidation, caspase 3 activation, and DNA damage ${ }^{33,68}$, leading to cell dysfunction ${ }^{69,70}$. The protective mechanisms toward oxidative stress mainly through balances mediated by non-enzymatic and enzymatic antioxidants ${ }^{71}$. In current study, the decrease in SOD and GPx activities of rats subjected to FIP might be due to the excess production of $\mathrm{O}_{2}$ that is rapidly transformed by SOD and GPx to $\mathrm{H}_{2} \mathrm{O}_{2}$ and water, respectively as reported in the liver of pregnant rats and their offspring due to the inadequate ROS detoxification produced by FIP in hepatocyte ${ }^{33,66}$.

It was recognized that liver cells showed the most active absorption and retention of CeNPs stored in the liver for eight weeks at least ${ }^{62,72,73}$. Recently ${ }^{62}$, demonstrated that the antioxidant activity of CeNPs was through increasing the antioxidant enzymes (SOD and GPx) with decreasing the lipid peroxidation markers (MDA and NO). CeNPs have a high ability to eliminate free radicals as soon as they are produced during ROS imbalance as they can inversely transform between $\mathrm{Ce}^{3+}$ and $\mathrm{Ce}^{4+}$ found on the surface ${ }^{74}$. The lipid peroxidation reduction after CeNPs administration diminishes ROS harmful effects on the hepatic tissue. The mechanism of scavenging of ROS/RNS of CeNPs depends on the physicochemical properties, the ability of CeNPs to absorb and release oxygen $^{75}$. CeNPs can act as a catalyst that mimics the antioxidant enzyme SOD ${ }^{76}$. So, there are two ways that CeNPs might act as an antioxidant against FIP toxicity. The first is linked to its antioxidant activity because the intensification of lipid peroxidation in the liver is among the causes of the inflammation, while the second is controlled by AMPK-PPAR- $\alpha$-signaling mechanism ${ }^{77}$. The inflammatory processes involved in the pathogenesis of liver damage and obesity-related NAFLD ${ }^{78}$. Furthermore, fat destroys liver tissues and induces neutrophil infiltration by releasing ROS and aggravating inflammatory processes ${ }^{12,13}$. High accumulation of neutral lipid (mostly TG in hepatic cell lipid droplets) begins the early NAFLD pathological stages ${ }^{79}$. NAFLD's pathogenesis is not well known but is suggested as a "two-hit" mechanism ${ }^{80}$. The first "hit" results in lipid aggregation and its mechanisms will likely include dysregulated lipid homeostasis such as de novo lipogenesis, $\beta$-oxidation, lipid storage and trafficking, and VLDL-c secretion ${ }^{81}$. This hepatic steatosis characterizes the liver to a "second hit" that results in inflammation, a primary pathophysiological symptom of steatohepatitis and advanced hepatic disorders $^{80,82}$. Oxidative stress has been suggested as the main mediator of this "second hit" $" 80,83$. So, increased FFAs levels accompanied by PPAR- $\alpha$ stimulation, which in turn leads to ROSproduction and cell injury ${ }^{81}$.

The efficiency of CeNPs on liver tissues was demonstrated by restoring the tissues architecture; necrosis, inflammation, and a decline of dystrophy in rats exposed to the FIP corroborated the histopathological lesions observed in the study ${ }^{84}$. FIP group revealing congested central vein, massive fatty degeneration in the periportal areas, lymphocytic aggregation in between massive fatty degeneration, with lymphocytic infiltration. Also, necrotic foci, congested liver sinusoids, and fatty degeneration might be due to that FIP increase lipid peroxidation. The FIP group that was protected with cerium nanoparticles showed normal liver architecture similar to the results of ${ }^{2}$. Studies showed an important connection between PCNA, Iba-1, and COX-2 expression and the inflammatory reaction as well as mitotic division ${ }^{85}$. Iba-1 participates in macrophage inflammatory pathways, including proliferation, migration, and signal transduction ${ }^{86}$. Proliferating cell nuclear antigen (PCNA) is believed to have an important role in controlling DNA synthesis as well as cell proliferation ${ }^{87}$. Also, COX isozymes (COX-1 and 2) are particularly important, as they are the main NSAIDs targets ${ }^{88}$, that parameters detected using the immunohistochemical.

In current study, Iba- 1 cells were observed in the FIP-treated group with strong PCNA and COX-2 reaction concentrated in the nuclei of the most hepatocytes that may be due to FIP induced liver injury while in case of FIP group that protected by CeNPs show low Iba-1 positive hepatic macrophage and nearly negative PCNA and COX-2 reaction in nuclei of the hepatocytes, So, liver regeneration is the expected physiological response. Also, FIP induces apoptosis by strong caspase 3 reaction in all nuclei of hepatocytes in opposite to FIP group previously protected with cerium showing very weak caspase 3 reaction in the nuclei of hepatocytes. That might be due to the cytotoxic activity of fatty acid that influences cell survival. Long term accumulation of lipids may lead to hepatocyte necrosis or apoptosis ${ }^{89}$. MDA and NO interacted directly with the DNA and triggered DNA adducts and nuclear condensation that promoted apoptosis via cytochrome $\mathrm{C}$ and further caspase 3 activations as detected by immunostaining, along with the induced mitochondrial dysfunction. Several reports revealed that FIP triggered cell death through apoptotic pathways ${ }^{20}$.

\section{Conclusions}

In this study, FIP induced hepatotoxicity through disturbance in the serum lipid profile (VLDL-c, HDL-c, TAG, LDL-c) and cholesterol level might be due to increasing the mRNA fatty acid-binding protein expression and ACC genes and FIP can cause serious tissue injury in the liver caused by oxidative stress through increasing MDA and NO with decreasing SOD and GPx and apoptosis formation by increment caspase 3 and decreasing BCL-2. While CeNPs could be used to activate the protective mechanisms against oxidative damage caused by FIP in the liver. Moreover, CeNPs effectively relieve the inflammatory processes in the blood of rats that may reduce obesity defects in liver damage. 
Received: 16 May 2020; Accepted: 7 December 2020

Published online: 14 January 2021

\section{References}

1. Al-Badran, A. A., Fujiwara, M., Gatlin, D. M. \& Mora, M. A. Lethal and sub-lethal effects of the insecticide fipronil on juvenile brown shrimp Farfantepenaeus aztecus. Sci. Rep. 8, 10769. https://doi.org/10.1038/s41598-018-29104-3 (2018).

2. Simon-Delso, N. et al. Systemic insecticides (neonicotinoids and fipronil): trends, uses, mode of action and metabolites. Environ. Sci. Pollut. Res. 22, 5-34 (2015).

3. Tavares, M. A. et al. Comparative effects of fipronil and its metabolites sulfone and desulfinyl on the isolated rat liver mitochondria. Environ. Toxicol. Pharmacol. 40, 206-214. https://doi.org/10.1016/j.etap.2015.06.013 (2015).

4. Bonneau, J. et al. SoK: Research Perspectives and Challenges for Bitcoin and Cryptocurrencies (Springer, New York, 2015).

5. Das, P. C., Cao, Y., Cherrington, N., Hodgson, E. \& Rose, R. L. Fipronil induces CYP isoforms and cytotoxicity in human hepatocytes. Chem. Biol. Interact. 164, 200-214 (2006).

6. Khan, S., Jan, M., Kumar, D. \& Telang, A. Firpronil induced spermotoxicity is associated with oxidative stress, DNA damage and apoptosis in male rats. Pestic. Biochem. Physiol. 124, 8-14 (2015).

7. Ahn, B.-E. \& Baker, T. A. Oxidization without substrate unfolding triggers proteolysis of the peroxide-sensor, PerR. Proc. Natl. Acad. Sci. 113, E23-E31 (2016).

8. Poljsak, B., Šuput, D. \& Milisav, I. Achieving the balance between ROS and antioxidants: when to use the synthetic antioxidants. Oxid. Med. Cell. Long. 2013 (2013).

9. Young, I. \& Woodside, J. Antioxidants in health and disease. J. Clin. Pathol. 54, 176-186 (2001).

10. Pizzimenti, S. et al. Interaction of aldehydes derived from lipid peroxidation and membrane proteins. Front. Physiol. 4, 242 (2013).

11. Diehl, A. M. Nonalcoholic fatty liver disease: implications for alcoholic liver disease pathogenesis. Alcohol. Clin. Exp. Res. 25, 8s-14s (2001).

12. Mittal, M., Siddiqui, M. R., Tran, K., Reddy, S. P. \& Malik, A. B. Reactive oxygen species in inflammation and tissue injury. Antioxid. Redox Signal. 20, 1126-1167 (2014).

13. Newsholme, P. et al. Molecular mechanisms of ROS production and oxidative stress in diabetes. Biochem. J. 473, 4527-4550. https ://doi.org/10.1042/bcj20160503c (2016).

14. Dahle, J. \& Arai, Y. Environmental geochemistry of cerium: applications and toxicology of cerium oxide nanoparticles. Int. J. Environ. Res. Public Health 12, 1253-1278 (2015).

15. $\mathrm{Xu}, \mathrm{C} . \& \mathrm{Qu}, \mathrm{X}$. Cerium oxide nanoparticle: a remarkably versatile rare earth nanomaterial for biological applications. NPG Asia Mater. 6, e90 (2014)

16. Dowding, J. M., Seal, S. \& Self, W. T. Cerium oxide nanoparticles accelerate the decay of peroxynitrite (ONOO-). Drug Deliv. Transl. Res. 3, 375-379 (2013).

17. Caputo, F., De Nicola, M. \& Ghibelli, L. Pharmacological potential of bioactive engineered nanomaterials. Biochem. Pharmacol. 92, 112-130. https://doi.org/10.1016/j.bcp.2014.08.015 (2014).

18. Olmedo, D. G., Tasat, D. R., Evelson, P., Guglielmotti, M. B. \& Cabrini, R. L. Biological response of tissues with macrophagic activity to titanium dioxide. J. Biomed. Mater. Res. A 84, 1087-1093 (2008).

19. Caballero, M. et al. Fipronil induces CYP isoforms in rats. Food Chem. Toxicol. 83, 215-221 (2015).

20. Abdel-Daim, M. M. \& Abdeen, A. Protective effects of rosuvastatin and vitamin E against fipronil-mediated oxidative damage and apoptosis in rat liver and kidney. Food Chem. Toxicol. 114, 69-77. https://doi.org/10.1016/j.fct.2018.01.055 (2018).

21. Khaksar, M. R. et al. Protective effects of cerium oxide and yttrium oxide nanoparticles on reduction of oxidative stress induced by sub-acute exposure to diazinon in the rat pancreas. J. Trace Elem. Med Biol. 41, 79-90 (2017).

22. Renaudin, J. Determination of Nitrite and Nitrate Content in Water (Springer, New York, 2001).

23. Nishikimi, M., Rao, N. A. \& Yagi, K. The occurrence of superoxide anion in the reaction of reduced phenazine methosulfate and molecular oxygen. Biochem. Biophys. Res. Commun. 46, 849-854 (1972).

24. Paglia, D. E. \& Valentine, W. N. Studies on the quantitative and qualitative characterization of erythrocyte glutathione peroxidase. J. Lab. Clin. Med. 70, 158-169 (1967).

25. Bancroft, J. D. \& Layton, C. in Bancroft s Theory and practice of histological techniques (ed Christopher Layton and John D. Bancroft S. Kim suvarna) 173-186 (Churchill Livingstone:, 2013).

26. 27Layton, C. \& Bancroft, J. D. in Bancroft s Theory and practice of histological techniques (ed C. Layton, J. D. B. S. Kim Suvarna) 215-238 (Churchill Livingstone, 2013).

27. Gibson-Corley, K. N., Olivier, A. K. \& Meyerholz, D. K. Principles for valid histopathologic scoring in research. Vet. Pathol. 50, 1007-1015. https://doi.org/10.1177/0300985813485099 (2013).

28. Noreldin, A. E. et al. Spatial distribution of osteoblast activating peptide in the rat stomach. Acta Histochem. 118, 109-117. https ://doi.org/10.1016/j.acthis.2015.12.001 (2016).

29. Noreldin, A. E., Elewa, Y. H. A., Kon, Y., Warita, K. \& Hosaka, Y. Z. Immunohistochemical localization of osteoblast activating peptide in the mouse kidney. Acta Histochem. 120, 323-328 (2018).

30. Sysel, A. M., Valli, V. E., Nagle, R. B. \& Bauer, J. A. Immunohistochemical quantification of the vitamin B12 transport protein (TCII), cell surface receptor (TCII-R) and Ki-67 in human tumor xenografts. Anticancer Res. 33, 4203-4212 (2013).

31. Vis, A. N., Kranse, R., Nigg, A. L. \& van der Kwast, T. H. Quantitative analysis of the decay of immunoreactivity in stored prostate needle biopsy sections. Am. J. Clin. Pathol. 113, 369-373. https://doi.org/10.1309/CQWY-E3F6-9KDN-YV36 (2000).

32. Badgujar, P. C., Pawar, N. N., Chandratre, G. A., Telang, A. \& Sharma, A. Fipronil induced oxidative stress in kidney and brain of mice: Protective effect of vitamin E and vitamin C. Pestic. Biochem. Physiol. 118, 10-18 (2015).

33. Romero, A. et al. Fipronil sulfone induced higher cytotoxicity than fipronil in SH-SY5Y cells: Protection by antioxidants. Toxicol. Lett. 252, 42-49 (2016).

34. Sun, Q. C., Clark, J. \& Park, Y. Environmental pollutants and type 2 diabetes: A review of human studies. Toxicol. Environ. Chem. 99, 1-42. https://doi.org/10.1080/02772248.2017.1393818 (2017).

35. Alves-Bezerra, M. \& Cohen, D. E. Triglyceride metabolism in the liver. Compr. Physiol. 8, 1-8. https://doi.org/10.1002/cphy.c1700 12 (2017).

36. Leung, T.-M. \& Nieto, N. CYP2E1 and oxidant stress in alcoholic and non-alcoholic fatty liver disease. J. Hepatol. 58, 395-398 (2013).

37. Gaggini, M. et al. Non-alcoholic fatty liver disease (NAFLD) and its connection with insulin resistance, dyslipidemia, atherosclerosis and coronary heart disease. Nutrients 5, 1544-1560 (2013).

38. Neuschwander-Tetri, B. A. Non-alcoholic fatty liver disease. BMC Med. 15, 45 (2017).

39. Donnelly, K. L. et al. Sources of fatty acids stored in liver and secreted via lipoproteins in patients with nonalcoholic fatty liver disease. J. Clin. Investig. 115, 1343-1351 (2005).

40. Hawley, S. A. et al. Use of cells expressing $\gamma$ subunit variants to identify diverse mechanisms of AMPK activation. Cell Metab. 11, 554-565 (2010).

41. Yin, W., Mu, J. \& Birnbaum, M. J. Role of AMP-activated protein kinase in cyclic AMP-dependent lipolysis in 3T3-L1 adipocytes. J. Biol. Chem. 278, 43074-43080 (2003). 
42. Koh, H.-J. et al. Adrenaline is a critical mediator of acute exercise-induced AMP-activated protein kinase activation in adipocytes. Biochem. J. 403, 473-481 (2007).

43. Trump, B. F. \& Berezesky, I. K. The role of cytosolic Ca2+ in cell injury, necrosis and apoptosis. Curr. Opin. Cell Biol. 4, 227-232 (1992).

44. Sun, Q. et al. Fipronil promotes adipogenesis via AMPKalpha-mediated pathway in 3T3-L1 adipocytes. Food Chem. Toxicol. 92, 217-223. https://doi.org/10.1016/j.fct.2016.04.011 (2016).

45. Sun, Q. et al. Fipronil promotes adipogenesis via AMPKa-mediated pathway in 3T3-L1 adipocytes. Food Chem. Toxicol. 92, 217-223 (2016).

46. Terra, X. et al. FABP 4 is associated with inflammatory markers and metabolic syndrome in morbidly obese women. Eur. J. Endocrinol. 164, 539-547 (2011).

47. Rocca, A. et al. Pilot in vivo investigation of cerium oxide nanoparticles as a novel anti-obesity pharmaceutical formulation. Nanomed. Nanotechnol. Biol. Med. 11, 1725-1734 (2015).

48. Arya, A. et al. Cerium oxide nanoparticles promote neurogenesis and abrogate hypoxia-induced memory impairment through AMPK-PKC-CBP signaling cascade. Int. J. Nanomed. 11, 1159 (2016).

49. Habinowski, S. A. \& Witters, L. A. The effects of AICAR on adipocyte differentiation of 3T3-L1 cells. Biochem. Biophys. Res. Commun. 286, 852-856 (2001).

50. Minokoshi, Y. et al. Leptin stimulates fatty-acid oxidation by activating AMP-activated protein kinase. Nature 415, 339-343. https ://doi.org/10.1038/415339a (2002).

51. Daval, M. et al. Anti-lipolytic action of AMP-activated protein kinase in rodent adipocytes. J. Biol. Chem. 280, 25250-25257 (2005).

52. Kobyliak, N. et al. Cerium dioxide nanoparticles possess anti-inflammatory properties in the conditions of the obesity-associated NAFLD in rats. Biomed. Pharmacother. 90, 608-614. https://doi.org/10.1016/j.biopha.2017.03.099 (2017).

53. Kersten, S. Integrated physiology and systems biology of PPARa. Mol. Metab. 3, 354-371 (2014).

54. Hashimoto, T. et al. Defect in peroxisome proliferator-activated receptor $\alpha$-inducible fatty acid oxidation determines the severity of hepatic steatosis in response to fasting. J. Biol. Chem. 275, 28918-28928 (2000).

55. Bookout, A. L. et al. Anatomical profiling of nuclear receptor expression reveals a hierarchical transcriptional network. Cell 126, 789-799 (2006).

56. Escher, P. et al. Rat PPARs: quantitative analysis in adult rat tissues and regulation in fasting and refeeding. Endocrinology 142, 4195-4202 (2001).

57. Patsouris, D., Reddy, J. K., Müller, M. \& Kersten, S. Peroxisome proliferator-activated receptor a mediates the effects of high-fat diet on hepatic gene expression. Endocrinology 147, 1508-1516 (2006).

58. Kim, S. et al. Hepatic gene expression profiles in a long-term high-fat diet-induced obesity mouse model. Gene 340, 99-109 (2004).

59. Peyrou, M., Ramadori, P., Bourgoin, L. \& Foti, M. PPARs in liver diseases and cancer: epigenetic regulation by MicroRNAs. PPAR Res. 2012, 16. https://doi.org/10.1155/2012/757803 (2012).

60. Mandard, S., Muller, M. \& Kersten, S. Peroxisome proliferator-activated receptor alpha target genes. Cell. Mol. Life Sci. 61, 393-416. https://doi.org/10.1007/s00018-003-3216-3 (2004).

61. Zhao, Q., Yang, R., Wang, J., Hu, D.-D. \& Li, F. PPARa activation protects against cholestatic liver injury. Sci. Rep. 7, 9967. https:// doi.org/10.1038/s41598-017-10524-6 (2017).

62. Oro, D. et al. Cerium oxide nanoparticles reduce steatosis, portal hypertension and display anti-inflammatory properties in rats with liver fibrosis. J. Hepatol. 64, 691-698. https://doi.org/10.1016/j.jhep.2015.10.020 (2016).

63. Berghe, W. V. et al. Peroxisomal Disorders and Regulation of Genes 181-196 (Springer, New York, 2003).

64. Ortiz-Ortiz, M. A. et al. Nitric oxide-mediated toxicity in paraquat-exposed SH-SY5Y cells: a protective role of 7-nitroindazole. Neurotox. Res. 16, 160-173 (2009).

65. Abdel-Daim, M. M. Synergistic protective role of ceftriaxone and ascorbic acid against subacute diazinon-induced nephrotoxicity in rats. Cytotechnology 68, 279-289 (2016).

66. Guelfi, M., Maioli, M. A., Tavares, M. A. \& Mingatto, F. E. Citotoxicity of fipronil on hepatocytes isolated from rat and effects of its biotransformation. Braz. Arch. Biol. Technol. 58, 843-853 (2015).

67. Karami-Mohajeri, S., Ahmadipour, A., Rahimi, H.-R. \& Abdollahi, M. Adverse effects of organophosphorus pesticides on the liver: a brief summary of four decades of research. Arhiv Rada Toksikol. 68, 261-275 (2017).

68. Zhang, B. et al. Fipronil induces apoptosis through caspase-dependent mitochondrial pathways in Drosophila S2 cells. Pestic. Biochem. Physiol. 119, 81-89. https://doi.org/10.1016/j.pestbp.2015.01.019 (2015).

69. Small, D. M., Coombes, J. S., Bennett, N., Johnson, D. W. \& Gobe, G. C. Oxidative stress, anti-oxidant therapies and chronic kidney disease. Nephrology 17, 311-321. https://doi.org/10.1111/j.1440-1797.2012.01572.x (2012).

70. Klaunig, J. E., Kamendulis, L. M. \& Hocevar, B. A. Oxidative stress and oxidative damage in carcinogenesis. Toxicol. Pathol. 38, 96-109. https://doi.org/10.1177/0192623309356453 (2010).

71. Abdollahi, M., Ranjbar, A., Shadnia, S., Nikfar, S. \& Rezaiee, A. Pesticides and oxidative stress: A review. Med. Sci. Monit. 10, 141-147 (2004).

72. Kumari, M., Kumari, S. I. \& Grover, P. Genotoxicity analysis of cerium oxide micro and nanoparticles in Wistar rats after 28 days of repeated oral administration. Mutagenesis 29, 467-479 (2014).

73. Saleh, H. et al. Chemo-protective potential of cerium oxide nanoparticles against fipronil-induced oxidative stress, apoptosis, inflammation and reproductive dysfunction in male white albino rats. Molecules 25, 3479 (2020).

74. Naganuma, T. \& Traversa, E. Stability of the Ce 3+ valence state in cerium oxide nanoparticle layers. Nanoscale 4, 4950-4953 (2012).

75. Deshpande, S., Patil, S., Kuchibhatla, S. V. \& Seal, S. Size dependency variation in lattice parameter and valency states in nanocrystalline cerium oxide. Appl. Phys. Lett. 87, 133113 (2005).

76. Hirst, S. M. et al. Anti-inflammatory properties of cerium oxide nanoparticles. Small 5, 2848-2856 (2009).

77. Kobyliak, N. et al. Cerium Dioxide Nanoparticles Possess Anti-inflammatory Properties in the Conditions of the Obesity-Associated NAFLD in Rats Vol. 90 (Springer, New York, 2017).

78. Tilg, H. The role of cytokines in non-alcoholic fatty liver disease. Dig. Dis. 28, 179-185 (2010).

79. Montagner, A. et al. Liver PPARa is crucial for whole-body fatty acid homeostasis and is protective against NAFLD. Gut 65, 1202-1214. https://doi.org/10.1136/gutjnl-2015-310798 (2016).

80. Salt, W. B. Nonalcoholic fatty liver disease (NAFLD): A comprehensive review. J. Insurance Med. 36, 27-41 (2004).

81. Saadeh, S. Nonalcoholic fatty liver disease and obesity. Nutr. Clin. Pract. 22, 1-10 (2007).

82. Day, C. P. \& James, O. F. W. Steatohepatitis: A tale of two \& \#x201c;hits”?. Gastroenterology 114, 842-845. https://doi.org/10.1016/ S0016-5085(98)70599-2 (1998).

83. Allard, J. P. et al. Nutritional assessment and hepatic fatty acid composition in non-alcoholic fatty liver disease (NAFLD): a crosssectional study. J. Hepatol. 48, 300-307. https://doi.org/10.1016/j.jhep.2007.09.009 (2008).

84. Amiri, F. T., Hamzeh, M., Beklar, S. Y. \& Hosseinimehr, S. J. Anti-apoptotic and antioxidant effect of cerium oxide nanoparticles on cyclophosphamide-induced hepatotoxicity. Erciyes Med. J. 40, 1-2 (2018).

85. Wang, D., Shi, J. Q. \& Liu, F. X. Immunohistochemical detection of proliferating cell nuclear antigen in hepatocellular carcinoma. World J. Gastroenterol. 3, 101-103. https://doi.org/10.3748/wjg.v3.i2.101 (1997). 
86. Tian, Y., Kelemen, S. E. \& Autieri, M. V. Inhibition of AIF-1 expression by constitutive siRNA expression reduces macrophage migration, proliferation, and signal transduction initiated by atherogenic stimuli. Am. J. Physiol. Cell Physiol. 290, C1083-1091. https://doi.org/10.1152/ajpcell.00381.2005 (2006).

87. Takasaki, Y., Deng, J.-S. \& Tan, E. M. A nuclear antigen associated with cell proliferation and blast transformation. J. Exp. Med. 154, 1899-1909 (1981).

88. Lee, Y., Rodriguez, C. \& Dionne, R. A. The role of COX-2 in acute pain and the use of selective COX-2 inhibitors for acute pain relief. Curr. Pharm. Des. 11, 1737-1755 (2005).

89. Miner, J. L., Cederberg, C. A., Nielsen, M. K., Chen, X. \& Baile, C. A. Conjugated linoleic acid (CLA), body fat, and apoptosis. Obes. Res. 9, 129-134 (2001).

\section{Acknowledgements}

The author would like to thank Ken Takeda (The Center for Environmental Health Science for The Next Generation, Research institute for Science and Technology, Organization for Research Advancement, Tokyo University of science, Japan) for providing Cerium nanoparticles. The authors gratefully acknowledge Ms. Amany Magdy Beshbishy (Mater degree, National research Center for Protozoans Diseases, Obihiro University of Agriculture and Veterinary Medicine, Japan) for helping in English editing.

\section{Author contributions}

L.W., A.M.K.N., Y.S.E., D.S. contributed to lab work, A.N., N.E., H.S., Y.H.A.E., S.M.A.H., A.A.S, contributed to Data analysis. A.M.K.N, Y.S.E., H.M.S. contributed to supervision, conceive, and designed the project. A.M.K.N, Y.S.E., H.F.H., G.E.B., M.U., H.M.S. writing the manuscript. All authors reviewed the manuscript.

\section{Funding}

This research received no external funding.

\section{Competing interests}

The authors declare no competing interests.

\section{Additional information}

Correspondence and requests for materials should be addressed to H.F.H., G.E.-S.B. or H.M.S.

Reprints and permissions information is available at www.nature.com/reprints.

Publisher's note Springer Nature remains neutral with regard to jurisdictional claims in published maps and institutional affiliations.

(c) (i) Open Access This article is licensed under a Creative Commons Attribution 4.0 International

License, which permits use, sharing, adaptation, distribution and reproduction in any medium or format, as long as you give appropriate credit to the original author(s) and the source, provide a link to the Creative Commons licence, and indicate if changes were made. The images or other third party material in this article are included in the article's Creative Commons licence, unless indicated otherwise in a credit line to the material. If material is not included in the article's Creative Commons licence and your intended use is not permitted by statutory regulation or exceeds the permitted use, you will need to obtain permission directly from the copyright holder. To view a copy of this licence, visit http://creativecommons.org/licenses/by/4.0/.

(C) The Author(s) 2021 